\title{
(3) Insights into the development of molecular therapies for craniosynostosis
}

\author{
Jennifer Kosty, MD, ${ }^{1}$ and Timothy W. Vogel, MD² \\ 'Department of Neurosurgery, University of Cincinnati; and 'Department of Neurosurgery, Cincinnati Children's Hospital and \\ Medical Center, Cincinnati, Ohio \\ For the past 2 decades, clinical and basic science researchers have gained significant insights into the molecular and \\ genetic pathways associated with common forms of craniosynostosis. This has led to invaluable information for families \\ and physicians in their attempts to understand the heterogeneity of craniosynostosis. Genetic mutations have been iden- \\ tified in the fibroblast growth factor receptors (FGFRs) as well as in other targets, including TWIST1, BMP, and RUNX2. \\ Greater understanding of these and other pathways has led to the development of innovative approaches for applying \\ medical therapies to the treatment of craniosynostosis, in particular by maintaining suture patency. In this article, the \\ authors discuss the molecular pathophysiological mechanisms underlying various forms of craniosynostosis. They also \\ highlight recent developments in the field of molecular craniosynostosis research with the hope of identifying targets for \\ medical therapies that might augment the results of surgical intervention.
}

http://thejns.org/doi/abs/10.3171/2015.2.FOCUS155

KEY WORDS craniosynostosis; fibroblast growth factor receptor; TWIST; genetics; molecular mechanisms; suture biology; therapy

$\mathrm{I}$ N 1993, Jabs et al. ${ }^{11}$ were the first to identify a genetic cause for craniosynostosis with the MSX2 gene mutation resulting in "Boston-type" craniosynostosis. Shortly thereafter, the role of fibroblast growth factor receptor (FGFR) in Crouzon syndrome was identified, ${ }^{35}$ and transforming growth factor $\beta$ (TGF $\beta$ ) was recognized as a powerful modulator of suture fusion. ${ }^{33}$ From these early investigations, our understanding of the molecular pathways contributing to craniosynostosis has greatly expanded, and additional molecular and genetic pathways continue to be recognized.

Contemporary treatment of craniosynostosis has seen a number of changes in the past 30 years. There have been significant studies performed on the neurocognitive outcomes associated with craniosynostosis that have helped craniofacial surgeons identify the need for early intervention. ${ }^{42}$ Along these lines, minimally invasive endoscopeassisted surgery has been developed, ${ }^{15}$ which has helped to treat children at younger ages with fewer comorbidities and costs associated with surgery. ${ }^{4}$ There remains, however, a $1 \%-2 \%$ mortality rate associated with open cranial vault remodeling and surgical approaches. ${ }^{38}$ The advent of molecular treatments in other area of medicine has been based on genetic analysis of an individual patient's profile for a particular phenotype. These same principles may be applicable to the field of craniosynostosis.

It is possible that exploitation of this pharmacological approach will, in the future, yield therapeutic targets to prevent premature suture refusion following craniosynostosis surgery, particularly in children with syndromic craniosynostosis. Premature fusion of sutures following surgery may lead to suboptimal cosmetic results, decreased intracranial volumes, and ultimately, neurological comorbidities prompting a surgical revision.

In this article, we review the current literature on the molecular mechanisms related to the development of craniosynostosis and discuss the most promising candidates for translational therapies (Table 1).

ABBREVIATIONS BMP = bone morphogenetic protein; ERK1/2 = extracellular signal-related kinases 1 and 2; FGFR = fibroblast growth factor receptor; SNP = single nucleotide polymorphism; TGF $\beta=$ transforming growth factor $\beta$.

SUBMITTED January 5, 2015. ACCEPTED February 12, 2015.

INCLUDE WHEN CITING DOI: 10.3171/2015.2.FOCUS155.

DISCLOSURE The authors report no conflict of interest concerning the materials or methods used in this study or the findings specified in this paper. 
TABLE 1. Molecular genetics of craniosynostosis and potential translational approaches

\begin{tabular}{|c|c|c|c|c|}
\hline $\begin{array}{l}\text { Signaling } \\
\text { Molecule }\end{array}$ & Type of Molecule & Associated Disorders & Translational Approaches & References \\
\hline FGFR1-3/FGFs & $\begin{array}{l}\text { Cell surface receptor/ } \\
\text { ligand }\end{array}$ & $\begin{array}{l}\text { Apert, Crouzon, Pfeiffer, Jackson-Weiss, } \\
\text { \& Muenke syndromes; nonsyndromic } \\
\text { craniosynostosis }\end{array}$ & $\begin{array}{l}\text { Soluble FGFR2 receptor, small hairpin RNA } \\
\text { interference, viral vector introduction of } \\
\text { dominant-negative receptor }\end{array}$ & $\begin{array}{c}9,23,27,35,36,40 \\
43,50,51,53\end{array}$ \\
\hline TWIST1 & Transcription factor & Saethre-Chotzen & Pending & 6 \\
\hline TGF $\beta$ & Cytokine & None & Anti-TGF $\beta 2$ antibody & $24,30-33$ \\
\hline RUNX2 & Transcription factor & Nonsyndromic craniosynostosis & Pending & 10,46 \\
\hline MSX2 & Transcription factor & Boston-type craniosynostosis & Pending & 12 \\
\hline Ephrin-B1 & Cytokine & Craniofrontonasal syndrome & Pending & 44 \\
\hline Erf & Transcription factor & Single- \& multisuture synostosis & Pending & 45 \\
\hline
\end{tabular}

\section{Biology of the Mammalian Skull}

In its most basic form, the mammalian skull is composed of 5 bones: the paired frontal bones, paired parietal bones, and the unpaired interparietal bone, which receives contributions from the squamous temporal bone and greater wing of the sphenoid. ${ }^{25}$ Whereas the parietal bones are derived from the paraxial mesoderm, the frontal bones derive from the neural crest. ${ }^{5,14}$ The interparietal bone receives both mesoderm and neural crest contributions.

The cranial vault forms by intramembranous ossification, whereby the mesenchymal tissue between bony fronts is recruited to ossify. The sutures form as the margins of developing bones approximate, and constitute major growth centers of the skull vault. ${ }^{27}$ The suture may be thought of as a complex of the osteogenic fronts of the calvarial bone plates, the mesenchyme spanning these 2 surfaces, the dura mater, and the pericranium (Fig. 1). ${ }^{25}$ All parts of this complex have been shown to affect skull growth. ${ }^{20}$ The coordinated growth of these centers is interdependent, and if a molecular abnormality occurs in their formation, craniosynostosis may result in premature skull fusion.

\section{The Role of FGFR/FGF}

Mutations in FGFRs, particularly FGFR2, have been linked to 5 of the most common craniosynostosis syndromes: Apert, Pfeiffer, Jackson-Weiss, Crouzon, and

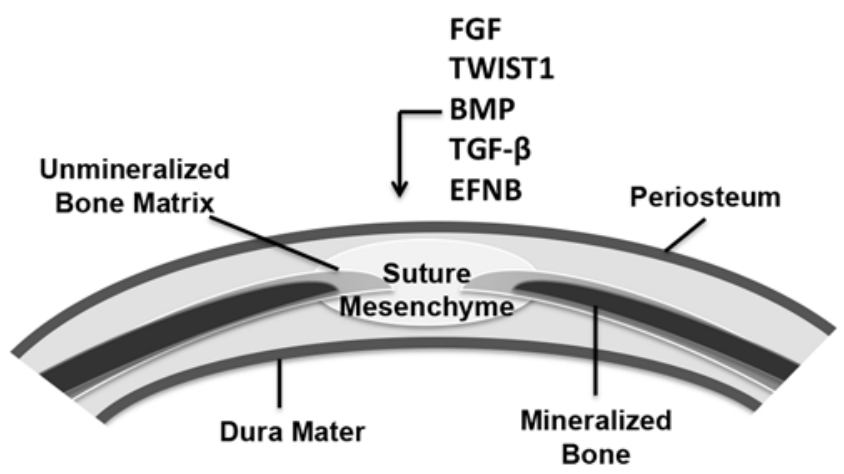

FIG. 1. Diagram of the biology of the human skull demonstrating the 2 osteogenic fronts with intervening mesenchyme, underlying dura, and overlying pericranium. Interactions between various molecular components regulate cranial suture development. EFNB = Ephrin-B1.
Muenke (Fig. 2). This has resulted in the FGFRs being the most studied proteins in the pathogenesis of craniosynostosis. The FGFR is composed of 3 extracellular immunoglobulin-like domains, 1 transmembrane domain, and 1 cytoplasmic tyrosine kinase domain. ${ }^{13}$ There are 4 human isoforms that interact with at least 22 FGFs. ${ }^{17,34}$ Of these, only FGFR1, 2, and 3 have been shown to contribute to the development of craniosynostosis. The FGFR1, 2, and 3 molecules have additional isoforms that are predominantly expressed in epithelial and mesenchymal tissues. ${ }^{4,17,29}$ Activation of these receptors results in dimerization and autophosphorylation, affecting multiple downstream pathways, including protein kinase C, Src, and canonical Wnt signaling. ${ }^{34}$

Most observed FGFR mutations affect the ligand-
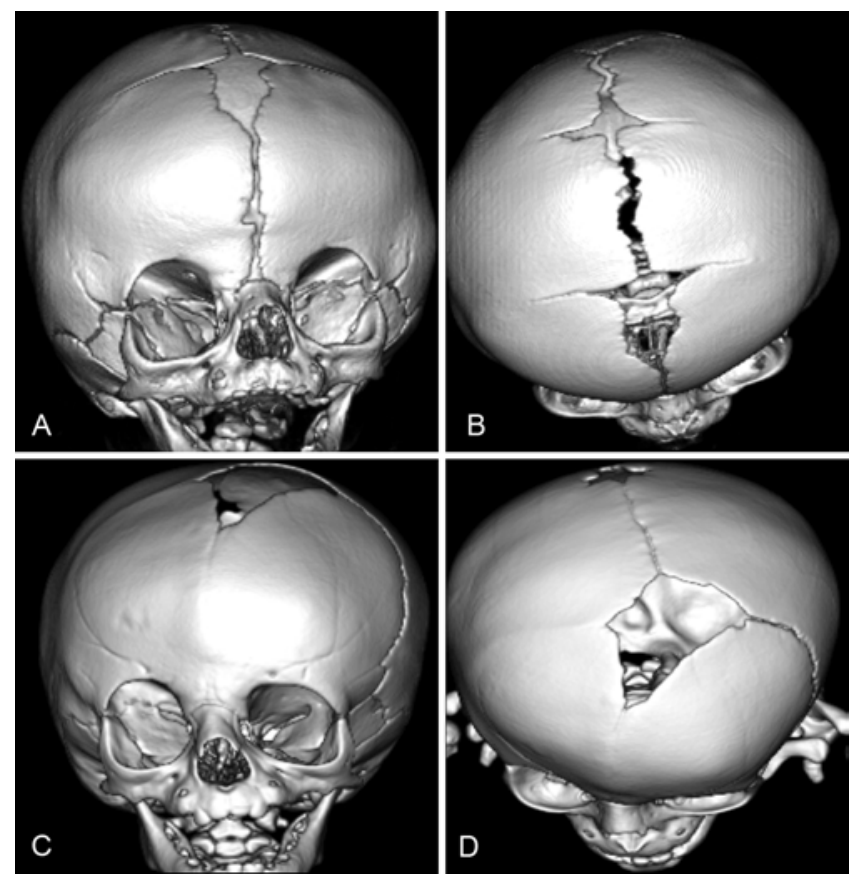

FIG. 2. Illustrative 3D head CT scans in 2 patients who had craniosynostosis with genetic syndromes. A: Frontal view demonstrating bicoronal synostosis in a patient affected by Muenke syndrome. B: Axial view of the same patient demonstrating brachycephaly. C: Frontal view demonstrating unicoronal synostosis in a patient affected by Saethre-Chotzen syndrome. D: Axial view of the same patient. 
binding domain, although a few affect the tyrosine kinase domain. ${ }^{49}$ These result in a gain of function through increasing ligand affinity, decreasing receptor specificity, or increasing intrinsic receptor activity. ${ }^{49}$ Several point mutations in the FGFRs have been identified. Mutations in FGFR2 (S252T and P253R) account for a majority of all Apert syndrome cases ${ }^{51}$ whereas multiple different cysteine substitutions in this receptor are associated with Crouzon syndrome. ${ }^{35,43}$ Mutations in FGFR1 (P252R) are associated with Pfeiffer syndrome, ${ }^{36}$ and changes in FGFR3 (P250R) are found in Muenke syndrome. ${ }^{27}$

In a recent series of 284 children with craniosynostosis, the FGFR3 (P250R) mutation accounted for 24\% of all genetic craniosynostoses and 5\% of the entire cohort. ${ }^{50}$ Others have reported this mutation in $31 \%$ of patients with nonsyndromic coronal craniosynostosis. ${ }^{23}$ The FGFR2 mutations (S252T and P253R) have also been reported in children with nonsyndromic craniosynostosis. ${ }^{50}$

Several translational animal models have been developed to study the effect of various FGFR mutations. Deletion of both FGFR1 and FGFR2 are lethal. ${ }^{25}$ Mice with gain-of-function mutation FGFR2 (Cys342Tyr) demonstrate a phenotype similar to Crouzon syndrome, with a shortened face, protruding eyes, and premature fusion of the coronal sutures. ${ }^{7}$ Bone marrow samples from this mouse model demonstrate proliferation of osteoprogenitor cells, suggesting the importance of FGFR2 in the early stages of osteocyte formation. A mouse model of Pfeiffer syndrome carrying the FGFR1 (P252R) mutation has also been developed. ${ }^{54}$ These mice exhibit premature sagittal and coronal suture fusion, midface hypoplasia, and facial asymmetry. Increased bone mineralization and elevated markers of bone formation are seen in these mice, suggesting that the FGFR1 plays a more important role in osteoblast differentiation.

Of all the FGF ligands, FGF2 seems to be most involved in suture fusion. ${ }^{20}$ Increases in FGF2 mRNA in translational models are seen in the dura mater underlying fused frontal sutures. Overexpression of FGF2 using a viral vector also causes premature fusion. ${ }^{26}$

Interference or downregulation of FGF at the suture interface is the most promising candidate for medical treatments of craniosynostosis. In an effort to inhibit FGF2 ligand signaling and maintain coronal suture patency in a model of Apert syndrome, Yokota et al. recently reported the capacity of a soluble FGFR2-impregnated nanogel to inhibit the actions of multiple ligands at the suture interface. ${ }^{53}$ Dominant-negative FGFRs, whose functional capacity are diminished, have been introduced in utero into animal models of craniosynostosis, and subsequent postnatal fusion of the cranial sutures were prevented. ${ }^{9}$ Additional forms of molecular FGF manipulation have also shown therapeutic potential through the use of RNA interference to prevent suture fusion in models of Apert syndrome,,$^{40}$ as well as treatment with MAP kinase inhibitors that inhibit premature suture fusion.

\section{The Role of TWIST1}

A transcription factor important for mesodermal patterning of the calvaria, TWISTI is located on chromosome
7. ${ }^{2}$ The gene was so named because fly embryos lacking this factor die with a twisted appearance. ${ }^{41}$ The TWIST1 gene is mutated in the majority of patients with SaethreChotzen syndrome. ${ }^{6}$ These patients demonstrate coronal craniosynostosis, facial asymmetry, prominent ear crura, and distal limb abnormalities (Fig. 2). ${ }^{6}$ Mutations of TWIST1 also have been documented in patients with nonsyndromic craniosynostosis. . $^{39,50}$

The TWIST1 protein is expressed in the osteoprogenitor cells within the coronal and sagittal sutures and is thought to be involved in osteoblast proliferation and differentiation. ${ }^{16}$ Unlike FGFR mutations, the mutations in this gene are generally missense or nonsense, resulting in loss of function..$^{20}$ Most if not all identified patients to date have been haploinsufficient.

In mice, homozygous deletion of TWISTI is lethal. ${ }^{28}$ Disruption of TWIST1 expression is thought to cause pathological conditions by interfering with osteoblast differentiation, at least partially by disrupting the RUNX2 pathway. ${ }^{20}$ The notch ligand Jaggedl also appears to be downstream of TWIST1, because TWIST1 mutants demonstrate decreased Jaggedl expression. ${ }^{52}$ Like TWIST1, Jaggedl localizes to mesoderm-derived cells that lie along the osteogenic-nonosteogenic boundary of the coronal suture. Conditional knockout of this protein leads to osteogenic differentiation and coronal craniosynostosis. ${ }^{52}$ Potential therapeutic approaches for TWIST-associated craniosynostosis may target delivery of the normal TWIST1 or Jagged1 protein to the cranial sutures.

\section{The Role of TGF $\beta$}

Although not associated with a known syndrome, TGF $\beta$ plays an integral role in cranial suture fusion. Analysis of tissue from normal and synostotic sutures of human infants undergoing cranial vault remodeling for single-suture synostosis demonstrated elevations of TGF $\beta$ immunoreactivity in the abnormal fused suture. ${ }^{37}$ Extracellular signal-related kinases 1 and 2 (ERK1/2) are important downstream actors of TGF $\beta 2$, because application of an ERK1/2 inhibitor disrupts TGF $\beta$-related suture fusion as well as ERK1/2 expression and phosphorylation. ${ }^{31}$

A series of studies by Opperman et al. demonstrated that TGF $\beta 1,2$, and 3 are expressed in developing sutures and dura. ${ }^{33}$ The TGF $\beta 2$ molecule seems to promote suture fusion, whereas TGF 33 promotes patency. ${ }^{31}$ Capitalizing on the therapeutic potential of TGF $\beta$, this group demonstrated that application of antibodies to TGF $\beta 2$ prevented normal molecular signaling and resulted in suture patency. ${ }^{30,32}$ Other studies have revealed that treatment of suturectomy sites in rabbits with anti-TGF $\beta 2$ antibodies can maintain suture patency. These also illustrate that greater intracranial volumes can be achieved several months after surgical suturectomy, suggesting a potential translational use in humans. ${ }^{24}$

\section{The Role of BMP}

A recent study of 130 infants with nonsyndromic sagittal synostosis highlights the role of bone morphogenetic proteins (BMPs) in craniosynostosis. The genomes of these patients were analyzed and compared with 450 con- 
trols to identify single nucleotide polymorphisms (SNPs) of interest. The most significantly linked SNPs were located in a region downstream of $B M P 2$, possibly a regulatory protein. In this study, BBS9, a component of a protein aggregation important for moving cargo molecules in and out of cilia, was also linked to craniosynostosis. ${ }^{18}$ Older studies have demonstrated disproportionately high expression of the BMP antagonist Noggin in patent sutures, with overexpression of this molecule resulting in failure of sutures to close. ${ }^{48}$ Treatment with Noggin or a similar BMP antagonist may also be critical to maintain suture patency following surgery.

\section{The Role of RUNX2}

The RUNX2 gene and its associated protein are master regulators of osteoblast differentiation and function. ${ }^{8}$ The RUNX2 gene is a downstream target of FGF, BMP, and TWIST1 proteins (Fig. 3). The Run $x 2^{-/-}$mice do not develop mature osteoblasts or bone ${ }^{19}$ whereas premature activation of $R U N X 2$ by insertion of the gene downstream of the paired related homeobox 1 (Prrx1) promoter is sufficient to cause calvarial intramembranous bone formation. ${ }^{22}$ Although no syndrome has been linked to this gene, there have been reports of a triplication and quadruplication of this gene resulting in dolichocephaly ${ }^{46}$ and pan-suture craniosynostosis, ${ }^{10}$ respectively. Its therapeutic potential is currently being investigated.

\section{Other Signaling Molecules}

The MSX2 gene mutation in Boston-type craniosynostosis, a syndrome now recognized in 2 families, ${ }^{12}$ was the first genetically linked craniosynostosis to be recognized. ${ }^{11}$ The $M S X 2$ gene is part of the homeobox-containing gene family and encodes a transcription factor that is important for pattern formation during development. The single-base mutation underlying Boston-type craniosynostosis increases the binding affinity of $M S X 2$, and accelerates suture formation. ${ }^{1}$ Transgenic mice expressing this mutation likewise express a craniosynostotic phenotype, reflecting the role of this protein in suture development. ${ }^{21}$ Despite the early identification of this gene, its role in craniosynostosis has been limited.

Ephrin-B1 (Efnbl), a membrane-anchored ligand for Eph receptor tyrosine kinase, has recently been linked to craniofrontonasal syndrome, an X-linked syndrome resulting in coronal craniosynostosis and marked hypertelorism, which is more pronounced in heterozygous females than males (Fig. 4). ${ }^{44}$ Multiple mutations from 24 different affected females were identified. In situ hybridization localizes EFNB1 mRNA to the developing murine

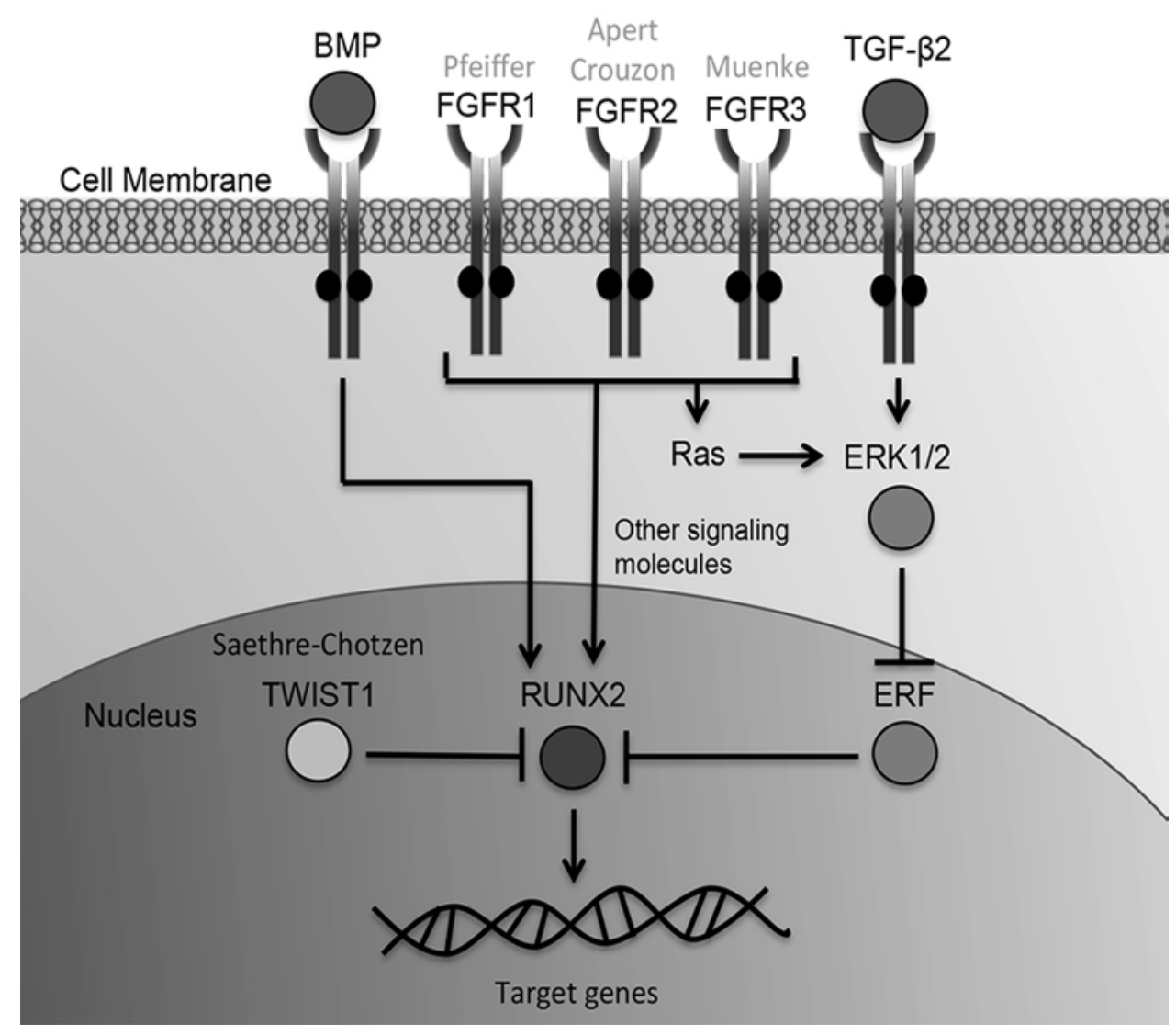

FIG. 3. Illustration of various molecular signaling pathways involved in craniosynostosis. Shown are the relationships between FGFRs, TGF 32 , BMP, and downstream signaling molecules TWIST1, ERK1/2, ERF, and RUNX2. Activating mutations of FGFRs may result in overactivity of RUNX2 as well as activation of ERK1/2. Similarly, TGF $\beta 2$ activation results in ERK1/2-mediated suture fusion. Activation of ERK1/2 leads to inhibition of ERF, an inhibitor of RUNX2. The RUNX2 molecule may also be activated by BMP, and inhibited by TWIST1. Overactivation of RUNX2 leads to premature suture fusion. ${ }^{8}$ 

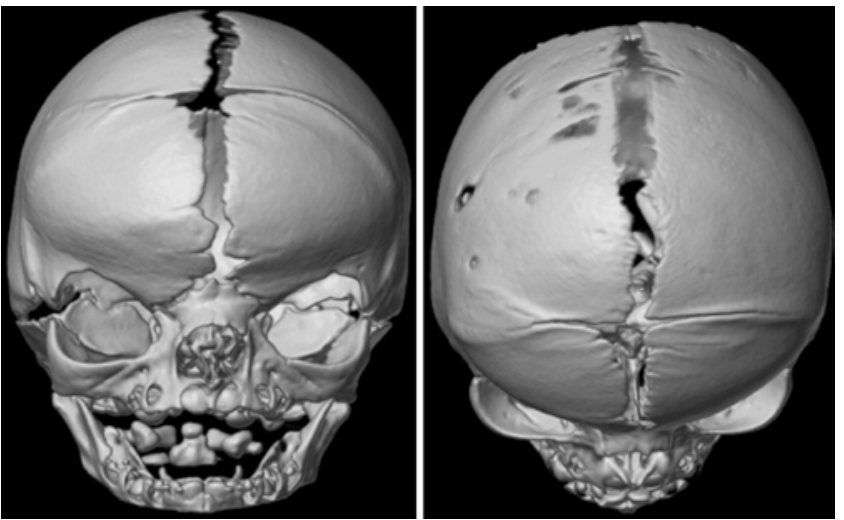

FIG. 4. Illustrative 3D head CT scans in a female patient with craniofrontonasal syndrome. Left: Frontal view revealing frontonasal abnormalities with hypertelorism. Right: Axial view revealing bilateral coronal craniosynostosis with brachycephaly.

coronal suture, suggesting a role for this protein in boundary formation.

Recent work has demonstrated that the Erf gene, whose protein is an inhibitory transcription factor and binding target of ERK1/2, may also be a cause of craniosynostosis (Fig. 3). ${ }^{45}$ Multiple mutations in the Erf gene have been demonstrated in a small group of patients exhibiting both single- and multisuture synostosis. These patients harbor monoallelic mutations, suggesting that the pathological mechanism is haploinsufficiency. In mice, Erf heterozygotes are normal, and Erf--- knockout mice are not viable, but mice engineered with a conditional knockout resulting in decreased Erf transcription demonstrate a domed head shape with multisuture synostosis.

\section{Discussion}

While the aforementioned molecular pathways are yielding innovative candidate therapies for forms of genetic craniosynostosis, the biology of nonsyndromic craniosynostosis, the most common form, remains elusive. Larger genome-wide studies of children affected by these forms of craniosynostosis will probably reveal new molecular targets. In addition, recent advances in cell biology have identified primary cilia as a signaling center coordinating the various molecular pathways responsible for craniofacial formation. ${ }^{3}$ Sonic hedgehog, Wnt, and FGF signaling are coordinated through primary cilia, and translational models have increasingly identified these cellular structures as potential therapeutic targets for various cranial pathological entities. ${ }^{47}$

Further exploration of the RUNX2, TWIST1, and ERK1/2 pathways is also likely to improve our understanding of both normal and pathological suture biology. Application of this knowledge will lead to the development of therapeutic agents that may eventually augment surgery for patients with craniosynostosis. The future of craniofacial surgery will be integrally involved in the development of medical therapies preventing premature bone fusion. Preventing or controlling bone fusion rates with medical treatments delivered locally and at the time of surgery may allow full cranial vault expansion along normal developmental timelines. The goal of such inter- ventions will be to reduce reoperation rates for cranial vault expansion. Agents that are to be used in a clinical setting must exhibit a low-risk safety profile, be capable of targeted delivery, and yield lasting effects throughout calvarial development.

\section{Conclusions}

Surgical treatment remains critical in the clinical care and outcome of patients affected by craniosynostosis; however, given the significant advances in our understanding of the biomolecular etiologies of suture development, there is the potential for innovative methods to treat and/ or prevent craniosynostosis. Fibroblast growth factor signaling and its role in the pathogenesis of craniosynostosis currently presents the most promising target for pharmacological manipulation of the craniosynostosis phenotype. The FGFRs remain the most important molecules in the pathological development of craniosynostosis, with mutations found in both syndromic and nonsyndromic patients alike. The TWIST1 and RUNX2 signaling pathways have emerged as important factors in suture formation, and will probably continue to yield information about the biology of suture fusion. With the expanded knowledge of the molecular mechanisms underlying premature suture fusion, the next generation of targeted molecular therapies in the treatment of craniosynostosis is on the horizon.

\section{References}

1. Bradley JP, Levine JP, Blewett C, Krummel T, McCarthy JG, Longaker MT: Studies in cranial suture biology: in vitro cranial suture fusion. Cleft Palate Craniofac J 33:150-156, 1996

2. Castanon I, Baylies MK: A Twist in fate: evolutionary comparison of Twist structure and function. Gene 287:11-22, 2002

3. Chang CF, Schock EN, O'Hare EA, Dodgson J, Cheng HH, Muir WM, et al: The cellular and molecular etiology of the craniofacial defects in the avian ciliopathic mutant talpid2. Development 141:3003-3012, 2014

4. Chellaiah AT, McEwen DG, Werner S, Xu J, Ornitz DM: Fibroblast growth factor receptor (FGFR) 3. Alternative splicing in immunoglobulin-like domain III creates a receptor highly specific for acidic FGF/FGF-1. J Biol Chem 269:11620-11627, 1994

5. Couly GF, Coltey PM, Le Douarin NM: The triple origin of skull in higher vertebrates: a study in quail-chick chimeras. Development 117:409-429, 1993

6. el Ghouzzi V, Le Merrer M, Perrin-Schmitt F, Lajeunie E, Benit P, Renier D, et al: Mutations of the TWIST gene in the Saethre-Chotzen syndrome. Nat Genet 15:42-46, 1997

7. Eswarakumar VP, Horowitz MC, Locklin R, Morriss-Kay GM, Lonai P: A gain-of-function mutation of Fgfr2c demonstrates the roles of this receptor variant in osteogenesis. Proc Natl Acad Sci U S A 101:12555-12560, 2004

8. Fitzpatrick DR: Filling in the gaps in cranial suture biology. Nat Genet 45:231-232, 2013

9. Greenwald JA, Mehrara BJ, Spector JA, Warren SM, Fagenholz PJ, Smith LE, et al: In vivo modulation of FGF biological activity alters cranial suture fate. Am J Pathol 158:441-452, 2001

10. Greives MR, Odessey EA, Waggoner DJ, Shenaq DS, Aradhya S, Mitchell A, et al: RUNX2 quadruplication: additional evidence toward a new form of syndromic craniosynostosis. J Craniofac Surg 24:126-129, 2013 
11. Jabs EW, Müller U, Li X, Ma L, Luo W, Haworth IS, et al: A mutation in the homeodomain of the human MSX2 gene in a family affected with autosomal dominant craniosynostosis. Cell 75:443-450, 1993

12. Janssen A, Hosen MJ, Jeannin P, Coucke PJ, De Paepe A, Vanakker OM: Second family with the Boston-type craniosynostosis syndrome: novel mutation and expansion of the clinical spectrum. Am J Med Genet A 161A:2352-2357, 2013

13. Jaye M, Schlessinger J, Dionne CA: Fibroblast growth factor receptor tyrosine kinases: molecular analysis and signal transduction. Biochim Biophys Acta 1135:185-199, 1992

14. Jiang X, Iseki S, Maxson RE, Sucov HM, Morriss-Kay GM: Tissue origins and interactions in the mammalian skull vault. Dev Biol 241:106-116, 2002

15. Jimenez DF, Barone CM, Cartwright CC, Baker L: Early management of craniosynostosis using endoscopic-assisted strip craniectomies and cranial orthotic molding therapy. Pediatrics 110:97-104, 2002

16. Johnson D, Iseki S, Wilkie AO, Morriss-Kay GM: Expression patterns of Twist and Fgfrl, -2 and -3 in the developing mouse coronal suture suggest a key role for twist in suture initiation and biogenesis. Mech Dev 91:341-345, 2000

17. Johnson DE, Williams LT: Structural and functional diversity in the FGF receptor multigene family. Adv Cancer Res 60:1-41, 1993

18. Justice CM, Yagnik G, Kim Y, Peter I, Jabs EW, Erazo M, et al: A genome-wide association study identifies susceptibility loci for nonsyndromic sagittal craniosynostosis near BMP2 and within BBS9. Nat Genet 44:1360-1364, 2012

19. Komori T, Yagi H, Nomura S, Yamaguchi A, Sasaki K, Deguchi K, et al: Targeted disruption of Cbfa1 results in a complete lack of bone formation owing to maturational arrest of osteoblasts. Cell 89:755-764, 1997

20. Lenton KA, Nacamuli RP, Wan DC, Helms JA, Longaker MT: Cranial suture biology. Curr Top Dev Biol 66:287-328, 2005

21. Liu YH, Kundu R, Wu L, Luo W, Ignelzi MA Jr, Snead ML, et al: Premature suture closure and ectopic cranial bone in mice expressing Msx 2 transgenes in the developing skull. Proc Natl Acad Sci U S A 92:6137-6141, 1995

22. Maeno T, Moriishi T, Yoshida CA, Komori H, Kanatani $\mathrm{N}$, Izumi S, et al: Early onset of Runx 2 expression caused craniosynostosis, ectopic bone formation, and limb defects. Bone 49:673-682, 2011

23. Moloney DM, Wall SA, Ashworth GJ, Oldridge M, Glass IA, Francomano CA, et al: Prevalence of Pro250Arg mutation of fibroblast growth factor receptor 3 in coronal craniosynostosis. Lancet 349:1059-1062, 1997

24. Mooney MP, Losken HW, Moursi AM, Shand JM, Cooper GM, Curry C, et al: Postoperative anti-Tgf-beta 2 antibody therapy improves intracranial volume and craniofacial growth in craniosynostotic rabbits. J Craniofac Surg 18:336-349, 2007

25. Morriss-Kay GM, Wilkie AO: Growth of the normal skull vault and its alteration in craniosynostosis: insights from human genetics and experimental studies. J Anat 207:637-653, 2005

26. Most D, Levine JP, Chang J, Sung J, McCarthy JG, Schendel SA, et al: Studies in cranial suture biology: up-regulation of transforming growth factor-beta1 and basic fibroblast growth factor mRNA correlates with posterior frontal cranial suture fusion in the rat. Plast Reconstr Surg 101:1431-1440, 1998

27. Muenke M, Gripp KW, McDonald-McGinn DM, Gaudenz $\mathrm{K}$, Whitaker LA, Bartlett SP, et al: A unique point mutation in the fibroblast growth factor receptor 3 gene (FGFR3) defines a new craniosynostosis syndrome. Am J Hum Genet 60:555-564, 1997

28. Nah H: Suture biology: Lessons from molecular genetics of craniosynostosis syndromes. Clin Orthod Res 3:37-45, 2000

29. Naski MC, Ornitz DM: FGF signaling in skeletal development. Front Biosci 3:d781-d794, 1998

30. Opperman LA, Chhabra A, Cho RW, Ogle RC: Cranial suture obliteration is induced by removal of transforming growth factor (TGF)-beta 3 activity and prevented by removal of TGF-beta 2 activity from fetal rat calvaria in vitro. J Craniofac Genet Dev Biol 19:164-173, 1999

31. Opperman LA, Fernandez CR, So S, Rawlins JT: Erk1/2 signaling is required for Tgf-beta 2-induced suture closure. Dev Dyn 235:1292-1299, 2006

32. Opperman LA, Moursi AM, Sayne JR, Wintergerst AM: Transforming growth factor-beta 3(Tgf-beta3) in a collagen gel delays fusion of the rat posterior interfrontal suture in vivo. Anat Rec 267:120-130, 2002

33. Opperman LA, Nolen AA, Ogle RC: TGF-beta 1, TGF-beta 2, and TGF-beta 3 exhibit distinct patterns of expression during cranial suture formation and obliteration in vivo and in vitro. J Bone Miner Res 12:301-310, 1997

34. Ornitz DM, Marie PJ: FGF signaling pathways in endochondral and intramembranous bone development and human genetic disease. Genes Dev 16:1446-1465, 2002

35. Reardon W, Winter RM, Rutland P, Pulleyn LJ, Jones BM, Malcolm S: Mutations in the fibroblast growth factor receptor 2 gene cause Crouzon syndrome. Nat Genet 8:98-103, 1994

36. Robin NH, Feldman GJ, Mitchell HF, Lorenz P, Wilroy RS, Zackai EH, et al: Linkage of Pfeiffer syndrome to chromosome 8 centromere and evidence for genetic heterogeneity. Hum Mol Genet 3:2153-2158, 1994

37. Roth DA, Gold LI, Han VK, McCarthy JG, Sung JJ, Wisoff $\mathrm{JH}$, et al: Immunolocalization of transforming growth factor beta 1, beta 2, and beta 3 and insulin-like growth factor I in premature cranial suture fusion. Plast Reconstr Surg 99:300-316, 1997

38. Senarath-Yapa K, Chung MT, McArdle A, Wong VW, Quarto N, Longaker MT, et al: Craniosynostosis: molecular pathways and future pharmacologic therapy. Organogenesis 8:103113,2012

39. Seto ML, Hing AV, Chang J, Hu M, Kapp-Simon KA, Patel $\mathrm{PK}$, et al: Isolated sagittal and coronal craniosynostosis associated with TWIST box mutations. Am J Med Genet A 143A:678-686, 2007

40. Shukla V, Coumoul X, Wang RH, Kim HS, Deng CX: RNA interference and inhibition of MEK-ERK signaling prevent abnormal skeletal phenotypes in a mouse model of craniosynostosis. Nat Genet 39:1145-1150, 2007

41. Simpson P: Maternal-zygotic gene interactions during formation of the dorsoventral pattern in Drosophila embryos. Genetics 105:615-632, 1983

42. Starr JR, Kapp-Simon KA, Cloonan YK, Collett BR, Cradock MM, Buono L, et al: Presurgical and postsurgical assessment of the neurodevelopment of infants with singlesuture craniosynostosis: comparison with controls. J Neurosurg 107 (2 Suppl):103-110, 2007

43. Steinberger D, Mulliken JB, Müller U: Predisposition for cysteine substitutions in the immunoglobulin-like chain of FGFR2 in Crouzon syndrome. Hum Genet 96:113-115, 1995

44. Twigg SR, Kan R, Babbs C, Bochukova EG, Robertson SP, Wall SA, et al: Mutations of ephrin-B1 (EFNB1), a marker of tissue boundary formation, cause craniofrontonasal syndrome. Proc Natl Acad Sci U S A 101:8652-8657, 2004

45. Twigg SR, Vorgia E, McGowan SJ, Peraki I, Fenwick AL, Sharma VP, et al: Reduced dosage of ERF causes complex craniosynostosis in humans and mice and links ERK1/2 signaling to regulation of osteogenesis. Nat Genet 45:308-313, 2013

46. Villa A, Gomez EG, Rodríguez L, Rastrollo RH, Martínez Tallo ME, Martínez-Frías ML: Interstitial tandem duplication 
of 6p: a case with partial trisomy (6)(p12p21.3). Am J Med Genet 90:369-375, 2000

47. Vogel TW, Carter CS, Abode-Iyamah K, Zhang Q, Robinson $\mathrm{S}$ : The role of primary cilia in the pathophysiology of neural tube defects. Neurosurg Focus 33(4):E2, 2012

48. Warren SM, Brunet LJ, Harland RM, Economides AN, Longaker MT: The BMP antagonist noggin regulates cranial suture fusion. Nature 422:625-629, 2003

49. Wilkie AO: Craniosynostosis: genes and mechanisms. Hum Mol Genet 6:1647-1656, 1997

50. Wilkie AO, Byren JC, Hurst JA, Jayamohan J, Johnson D, Knight SJ, et al: Prevalence and complications of single-gene and chromosomal disorders in craniosynostosis. Pediatrics 126:e391-e400, 2010

51. Wilkie AO, Slaney SF, Oldridge M, Poole MD, Ashworth GJ, Hockley AD, et al: Apert syndrome results from localized mutations of FGFR2 and is allelic with Crouzon syndrome. Nat Genet 9:165-172, 1995

52. Yen HY, Ting MC, Maxson RE: Jagged1 functions downstream of Twist1 in the specification of the coronal suture and the formation of a boundary between osteogenic and nonosteogenic cells. Dev Biol 347:258-270, 2010
53. Yokota M, Kobayashi Y, Morita J, Suzuki H, Hashimoto Y, Sasaki Y, et al: Therapeutic effect of nanogel-based delivery of soluble FGFR2 with S252W mutation on craniosynostosis. PLoS ONE 9:e101693, 2014

54. Zhou YX, Xu X, Chen L, Li C, Brodie SG, Deng CX: A Pro250Arg substitution in mouse Fgfrl causes increased expression of Cbfa1 and premature fusion of calvarial sutures. Hum Mol Genet 9:2001-2008, 2000

\section{Author Contributions}

Conception and design: both authors. Drafting the article: Kosty. Critically revising the article: both authors. Reviewed submitted version of manuscript: Kosty. Approved the final version of the manuscript on behalf of both authors: Kosty.

\section{Correspondence}

Jennifer Kosty, Department of Neurosurgery, University of Cincinnati, 260 Stetson St., Cincinnati, OH 45267. email: jennifer. kosty@gmail.com. 